\title{
LOW-FREQUENCY NOISE CHARACTERISTICS OF HIGH-POWER WHITE LED DURING LONG-TERM AGING EXPERIMENT
}

\author{
J. Glemža, J. Matukas, S. Pralgauskaitė, and V. Palenskis \\ Institute of Applied Electrodynamics and Telecommunications, Vilnius University, Sauletekio 3, 10257 Vilnius, Lithuania \\ Email: justinas.glemza@ff.vu.lt; jonas.matukas@ff.vu.lt; sandra.pralgauskaite@ff.vu.lt; vilius.palenskis@ff.vu.lt
}

Received 27 October 2017; revised 27 November 2017; accepted 21 June 2018

\begin{abstract}
Low-frequency electrical and optical noise characteristics of a high power white InGaN LED and the cross-correlation coefficient between these fluctuations are investigated during the long-term ageing experiment $(28000 \mathrm{~h})$. The analysis of cross-correlation shows that the correlated part of the low-frequency electrical noise, which indicates physical processes in the active area of the LED, varies during the ageing experiment. Two main stages are distinguished considering the rapid changes of the noise characteristics. The initial stage (after the first $1100 \mathrm{~h}$ ) is followed by the decrease in the noise power at low forward currents and the increase in the light output. The final stage (after $28000 \mathrm{~h}$ ) is characterized by a strong growth of the low-frequency noise, the decrease of the light output and the increase of the correlated part of electrical and optical fluctuations. These changes mean a failure in the active layer of the LED. The optical output decomposition into two spectral parts, the radiation generated by the LED chip and the radiation generated by the phosphor layer, enables evaluation of the phosphor layer influence on the degradation process of device optical characteristics. Despite the fact that this layer contributes to the variation of the LED chromatic properties, the cross-correlation analysis has shown that the phosphor layer does not act as a possible noise source during the ageing experiment.
\end{abstract}

Keywords: ageing, cross-correlation coefficient, electrical noise, light-emitting diode, optical noise

PACS: $72.70 .+\mathrm{m}, 85.60 . \mathrm{Jb}$

\section{Introduction}

Advantages such as excellent optical quality, high efficiency and eco-friendliness make the white lightemitting diodes (LED) a superior replacement for traditional light sources, and that is why they are widely used in a variety of applications, e.g. solid state lighting, signalling, automotive industry, etc. [1-3]. Phosphor-converted white LEDs are very attractive and suitable for massive production due to their low price and a quite high colour rendering index ( 80) which is appropriate in most situations [1]. There a semiconductor, mostly GaN-based, chip generates blue light and phosphors, usually yttrium-aluminium-garnet (YAG), produce an efficient broad yellow emission.
Despite wide manufacturing and application of white LEDs, their reliability investigation is still of high importance [3, 4. While most standards of the LED industry for lifetime assessment are based on lumen maintenance [5], investigation of electrical characteristics is not less important [3]. Various processes, like growth of non-radiative recombination, instabilities of dopants or impurities, increase of thermal resistance, etc., accelerate $\mathrm{GaN}$-based optoelectronic device degradation and lower performance [2]. Therefore, there is a demand for a sensitive diagnostic tool for both optical and electrical LED characterization. As modern LEDs have a complex structure, evaluating which part of the device is degrading is of high importance as well. 
Low-frequency noise spectroscopy is a suitable candidate for such diagnostics. It is well known that excess noise in a semiconductor device is caused by defects, structural non-idealities and fabrication imperfections. The essential feature of low-frequency noise spectroscopy is that measurements are performed under normal bias conditions near the equilibrium state and are nondestructive [6, 价. Due to this reason, the lowfrequency noise characteristics of GaN-based LEDs are of high interest to scientific community [8-12]. However, there are practically no published investigations on the low-frequency noise characteristics of white LEDs during a long ageing experiment at room temperature and manufacturer permissible forward current. This is in contrast to highly accelerated testing techniques [2, 13] where usually both high temperature and forward current are degradation accelerating factors. What is more, the analysis of the cross-correlation method helps to determine which part of the cross-correlation coefficient between electrical and optical fluctuations is generated by the lowfrequency fluctuations with $1 / f, 1 / f^{\alpha}$ or Lorentzian type spectra and to identify the location of possible noise sources in the structure of LED: active or peripheral layers [10, 14]. As a white LED has an additional structural component - the phosphor layer, it also has a role in the device degradation process and could act as a possible optical noise source. Thus, it is necessary to separate the optical spectrum of the white LED into the radiation generated by the LED chip and by the phosphor layer in order to evaluate which structural element of the white LED leads to optical and electrical fluctuations.

The aim of this work was to clear up the sources of the high power white LED degradation, their appearance and influence on the low-frequency noise characteristics during the long-term ageing.

\section{Experimental details}

The paper presents the investigation results of a modern design high power $(1 \mathrm{~W})$ phosphor-converted 'cool' white multi-quantum well (MQW) InGaN LED.

Low-frequency $10 \mathrm{~Hz}-20 \mathrm{kHz}$ voltage noise spectral density (optical noise is the emitted light power fluctuations and is detected by a photodiode; electrical noise is the light emitting diode voltage fluctuations) and the cross-correlation coefficient between optical and electrical fluctuations have been measured under CW operation at room temperature ( $293 \mathrm{~K}$ ). Figure 1 shows the measurement circuit for a simultaneous investigation of two noise signals: optical and electrical. Each noise measurement channel has a low-noise amplifier, a filter system and an analog-to-digital converter NI PCI-6115. The current generator mode is guaranteed for the LED under test by choosing the appropriate bias voltage and the load resistance. Noise characteristic measurements were carried out in a special screened laboratory room (Faraday cage) in order to avoid interferences from the extrinsic electromagnetic field.
Fig. 1. The two-channel noise measurement system: LED, the light emitting diode under test; PD1 and PD2, BSR and RSR photodetectors, respectively; $R_{\mathrm{LED} \text { load }}, R_{\mathrm{PD} 1 \text { load }}$ and $R_{\mathrm{PD} 2 \text { load }}$ load resistances; $R_{\text {ref1 }}$ and $R_{\text {ref2 }}$, reference resistors; LNA, a low-noise amplifier; F, a filter system; PC, a personal computer; PCI61115 , an analog-to-digital converter.

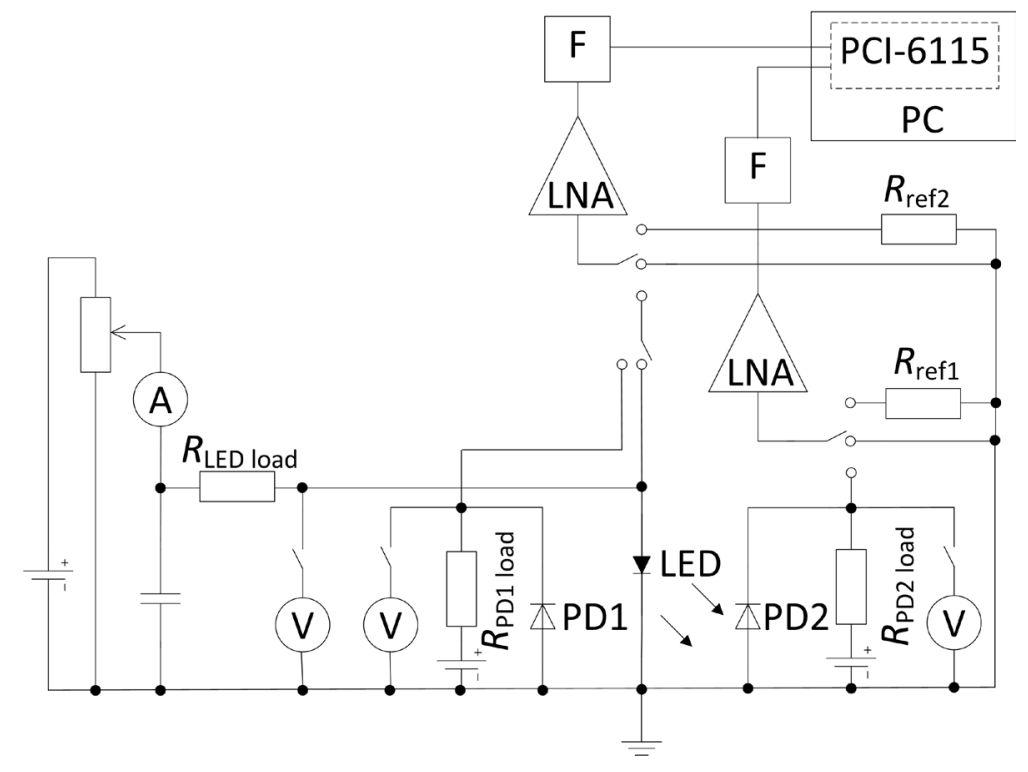


The spectral density of voltage fluctuations is estimated by using the Fast Fourier Transform. The absolute value of the measured noise voltage spectral density is calculated by comparing it with the thermal noise of the reference resistance, $R_{\text {ref }}$;

$$
S_{U}=\frac{\left\langle u_{\mathrm{LD}}^{2}(t)\right\rangle-\left\langle u_{\mathrm{syst}}^{2}(t)\right\rangle}{\left\langle u_{\mathrm{ref}}^{2}(t)\right\rangle-\left\langle u_{\mathrm{syst}}^{2}(t)\right\rangle} 4 k T_{0} R_{\mathrm{ref}} .
$$

Here $\left\langle u_{\mathrm{LD}}^{2}(t)\right\rangle,\left\langle u_{\mathrm{sys}}^{2}(t)\right\rangle$ and $\left\langle u_{\mathrm{ref}}^{2}(t)\right\rangle$ are, respectively, the variances of the noise signals of the LED, the measuring system, and the thermal noise of the reference resistor in the narrow frequency band $\Delta f ; T_{0}$ is the absolute temperature of the reference resistor.

A simultaneous operation of two identical noise measurement channels enables one to measure the cross-correlation coefficient between optical and electrical fluctuations. The simultaneous cross-correlation coefficient was measured not only in the overall investigated frequency region $(10 \mathrm{~Hz}-20 \mathrm{kHz})$ but also in every one-octave frequency range by using digital filters and was computed by the following expression:

$$
k=\frac{\left\langle u_{\mathrm{el}}(t) \cdot u_{\mathrm{op}}(t)\right\rangle}{\left(\sigma_{\mathrm{el}}^{2} \cdot \sigma_{\mathrm{op}}^{2}\right)^{1 / 2}} .
$$

Here brackets $\langle\ldots\rangle$ mean averaging both on time and on the number of realizations, $\sigma_{\mathrm{el}}^{2}=\left\langle u_{\mathrm{el}}^{2}(t)\right\rangle$ and $\sigma_{\mathrm{op}}^{2}=\left\langle u_{\mathrm{op}}^{2}(t)\right\rangle$ are the variances of electrical and optical fluctuations in the investigated frequency range, respectively.

Optical characteristics of the investigated LED were measured with a Si photodiodes matrix Hamamatsu S9702 which consists of three parts sensitive to different regions of the visible light spectrum: the blue spectral range (BSR) with the peak sensitivity wavelength $\lambda_{\mathrm{p}}=460 \mathrm{~nm}$, the green range (GSR) with $\lambda_{\mathrm{p} G}=540 \mathrm{~nm}$ and the red one (RSR) with $\lambda_{p R}=620 \mathrm{~nm}$. The BSR diode is sensitive to the light coming out from the active layer of the LED chip while GSR and RSR diodes are sensitive to the luminescence from the phosphor layer. In this work the results measured with BSR and RSR diodes are presented, as spectral response ranges of these photodiodes do not overlap and physical processes occurring in different parts of the white LED structure (i. e. the active area and the phosphor layer) can be properly separated.
The ageing experiment was performed at room temperature at the maximum manufacturer-allowed forward current $(350 \mathrm{~mA})$. The currentvoltage $(I-V)$, the light output power (which is proportional to the photovoltage $U_{\text {photo }}$ on the load resistance of a photodetector), noise characteristics and optical spectra measurements were periodically performed upon interrupting the ageing procedure.

\section{Results and discussion}

\subsection{Noise characteristics of unaged LED}

The measurement results have shown that electrical fluctuations of the investigated LED are characterized by $1 / f^{\alpha}$-type noise, where $\alpha$ is close to 1 (Fig. 2(a)). In the majority of semiconductor devices $1 / f^{\alpha}$-type fluctuations originate from a superposition of many charge carrier generation-recombination $(g-r)$ processes in the capture centres with widely distributed relaxation times [15]. These centres are formed during device fabrication and also during ageing due to the device degradation. The noise voltage spectral density of electrical fluctuations, $S_{U \text { el }}$, decreases as the forward current increases up to $10 \mathrm{~mA}$. After that, the electrical noise level increases (the inset in Fig. 2 (a)). This can be explained as follows. For the $p n$ junction the flowing current, $I$, is proportional to the total free charge carrier number in the sample, $N: I \sim N$. Therefore, the current fluctuation spectral density, $S_{T}$, is proportional to the current. The differential resistance of the diode $R_{\mathrm{d}} \sim 1 / I$, thus the voltage spectral density is inversely proportional to the current: $S_{U} \sim S_{I} R_{\mathrm{d}}^{2} \sim 1 / I$. When $I \approx 10 \mathrm{~mA}, R_{\mathrm{d}}$ reaches the serial resistance value $R_{\mathrm{s}}$, which is practically constant, and $S_{U} \sim I^{2}$.

Optical noise spectra are characterized by a weak $1 / f^{\alpha}$-type component that dominates up to $100 \mathrm{~Hz}$ and the 'white' noise (Fig. 2(b)). This 'white' noise can be attributed to the shot noise as its level depends on the light output power of the LED and is caused by the random photon emission process. The decrease of the normalized optical noise spectral density with the forward current increase is determined by the light output power increase (the inset in Fig. 2(b)).

The cross-correlation measurement and the analysis broaden the information obtained from noise 


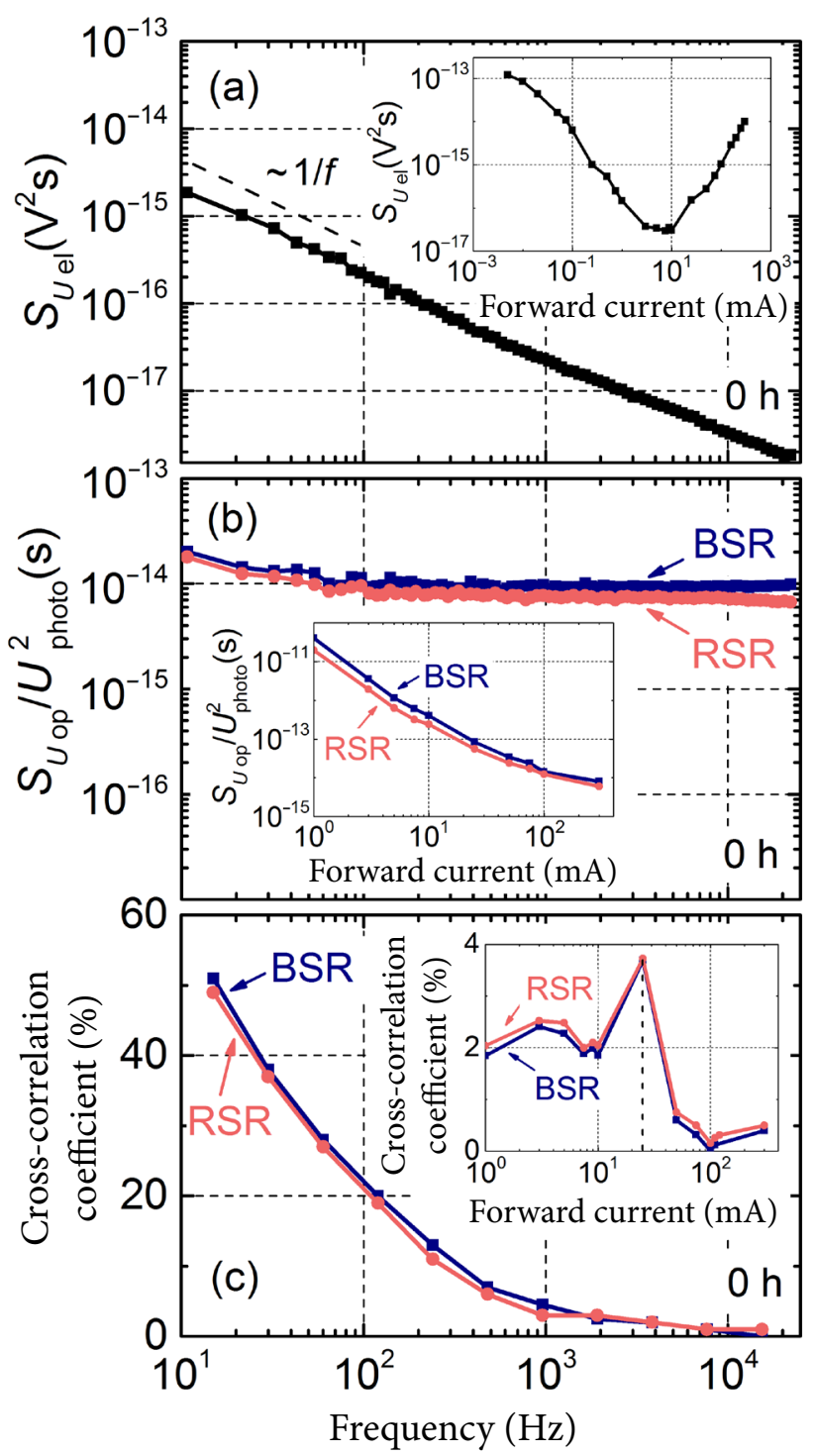

Fig. 2. Electrical (a) and optical (b) noise spectra at $100 \mathrm{~mA}$ forward current and (c) the cross-correlation coefficient between electrical and optical fluctuations at $25 \mathrm{~mA}$ forward current before ageing $(0 \mathrm{~h})$. Insets of (a) and (b) show the dependences of the voltage spectral density of electrical $\left(S_{U \mathrm{Ue}}\right)$ and normalized optical $\left(S_{U \text { Uop }} / U_{\text {photo }}^{2}\right)$ noise on the forward current at $22 \mathrm{~Hz}$, while the inset of (c) shows the cross-correlation coefficient dependence on the forward current in the overall frequency range $10 \mathrm{~Hz}-20 \mathrm{kHz}$. There the normalized optical noise and the cross-correlation coefficient are presented for both spectral ranges of the photodiode (BSR and RSR).

characteristics. As seen from Fig. 2(c), the crosscorrelation coefficient between electrical and optical noise signals is largest at low frequencies where $1 / f^{\alpha}$-type fluctuations dominate in both electrical and optical noise spectra. This positive cross-correlation coefficient indicates that the observed $1 / f^{\alpha}$-type electrical and optical fluctuations are caused by defects in the active region (QWs area) of the LED: defects modulate randomly the free charge carrier number in the QWs region and, as a consequence, lead to the photon number (optical) fluctuations in the same phase as electrical ones. Electrical and optical fluctuations are not completely correlated at low frequencies because fluctuations at contacts or electrical noise from the passive layers of the LED do not influence the emitted light fluctuations, i.e. the voltage noise spectral density of electrical noise can be written as a sum of correlated and uncorrelated (to the optical fluctuations) parts [14].

However, the 'white' noise in the optical fluctuations does not correlate with the $1 / f^{\alpha}$-type electrical noise and due to this the cross-correlation coefficient in all investigated frequency range of the unaged LED is rather small - the maximum value is $\sim 4 \%$ at $25 \mathrm{~mA}$ forward current as shown in the inset of Fig. 2(c).

\subsection{Noise characteristics during the ageing experiment}

This section represents the changes of noise characteristics (intensity, spectrum, cross-correlation coefficient) and their link to current-voltage $(I-V)$ and light output characteristics.

Long-term (in total $28000 \mathrm{~h}$ ) ageing was performed and two main stages could be distinguished where a significant change in electrical and optical noise intensity occurs: the initial stage just after the first $1100 \mathrm{~h}$ ageing and the final stage after $28000 \mathrm{~h}$. After $28000 \mathrm{~h}$ of operation the light output of the investigated LED decreases to $65 \%$ of the initial value at the currents above $1 \mathrm{~mA}$ (measured in BSR, Fig. 3). Usually, the decrease of the initial lumen output by $30 \%$ is the threshold when the human eye notices a light output reduction and this time, required to reach $70 \%$ of the initial lumen output, is called a lifetime of the LED (Alliance for Solid State Illumination System and Technology, TM-21 [1]). Therefore, we consider that the LED went out of order after $28000 \mathrm{~h}$ of ageing.

The investigated sample demonstrates a good linearity of the light output vs current characteristics before and after the ageing experiment 


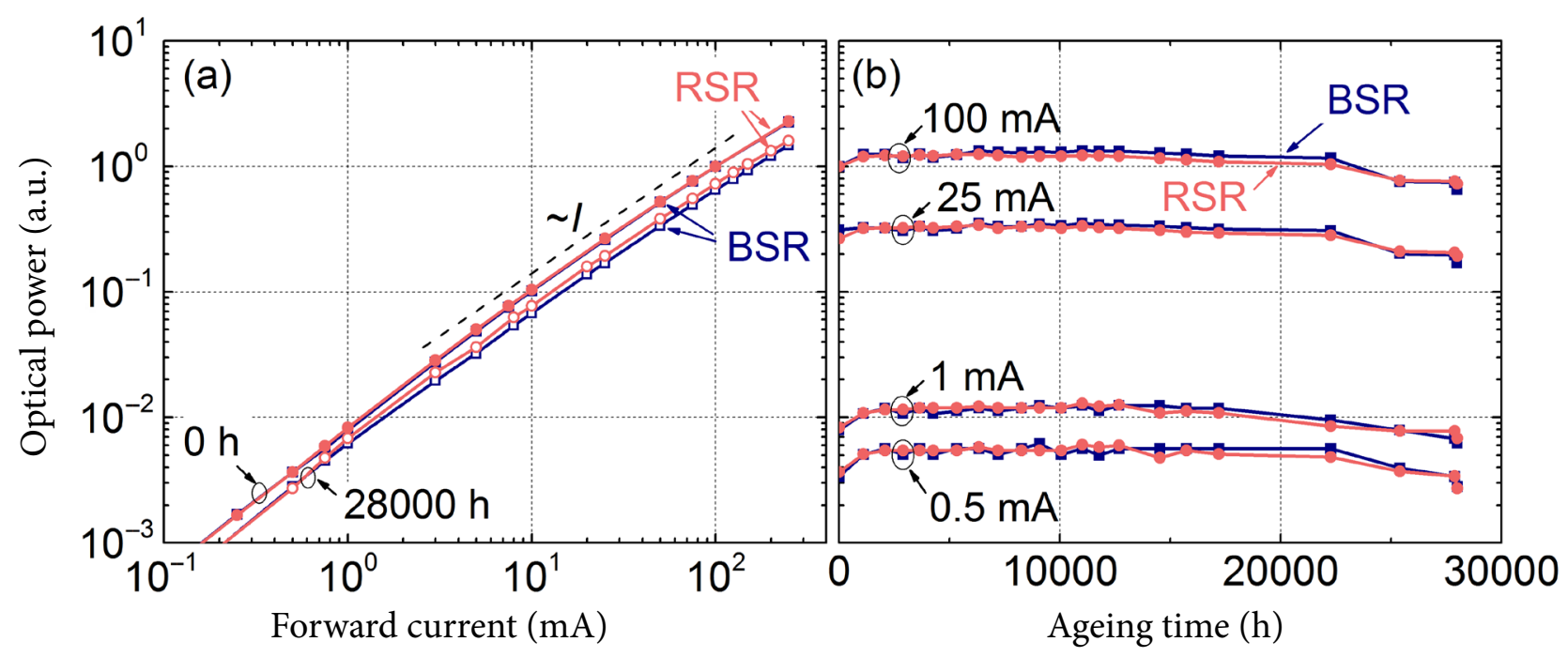

Fig. 3. The light output power dependences on the forward current at different ageing time (a): $0 \mathrm{~h}$ (solid symbols), $28000 \mathrm{~h}$ (open symbols); and on the ageing time at different forward current values (b) for both spectral ranges of the photodiode: BSR and RSR.

(Fig. $3(\mathrm{a}))$. At the early stage $(1100 \mathrm{~h})$ of ageing the LED output power increases by approximately $20 \%$ compared to the initial value (Fig. 3(b)). This suggests that small changes of the potential barrier occur in the active layer of the device that determine the increase of the charge carriers flow to the quantum wells and, as a consequence, a more intensive charge carrier recombination in the QWs region produces a more intensive light emission [16].

In order to understand changes of electrical fluctuations during ageing it is necessary to analyse the $I-V$ characteristics of the device. These characteristics of the LED (Fig. 4) can be modelled as for a typical diode, which consists of the $p$ - $n$ junction differential resistance $R_{\mathrm{d}}$, contact resistance $R_{\mathrm{s}}$ and parallel leakage resistance $R_{\mathrm{p}}$. As demonstrated in the inset of Fig. 4, the evident leakage current is dominant up to $0.01 \mathrm{~mA}$ and the deviation from the exponential law at forward current values higher than $20 \mathrm{~mA}$ is due to the series resistance of the LED. Knowing current values where these different carrier transport mechanisms dominate makes the interpretation of electrical noise characteristics easier.

The variation of electrical noise intensity during the ageing is represented in Fig. 5(a). During the ageing electrical noise spectra remained

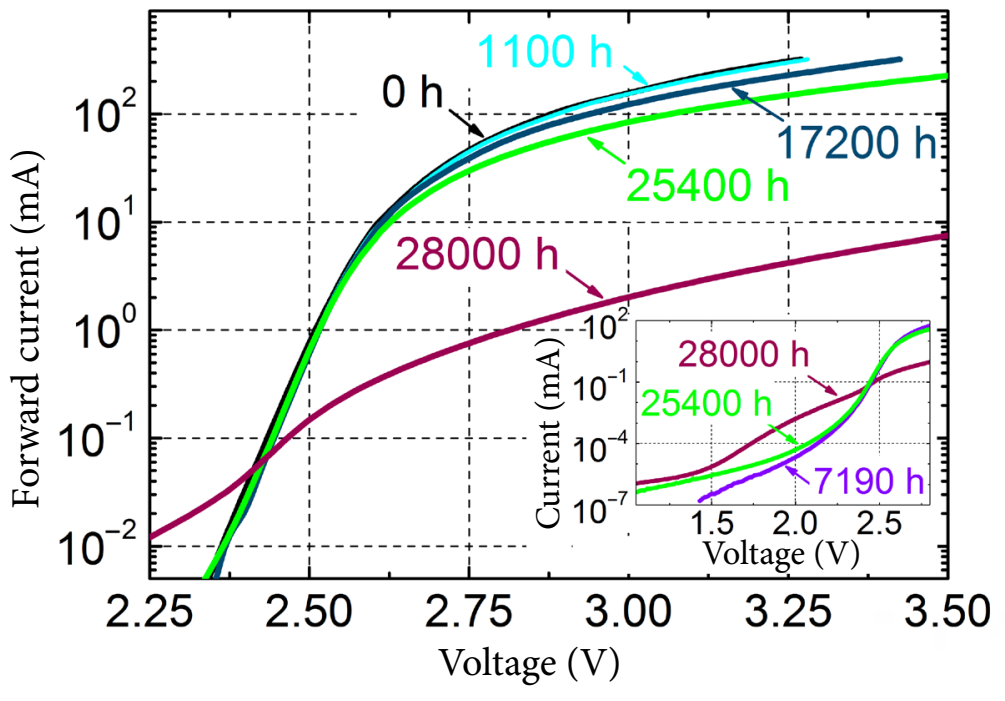

Fig. 4. $I-V$ characteristics of the investigated LED at different ageing times. The inset represents $I-V$ characteristics at the small current region (leakage currents). 


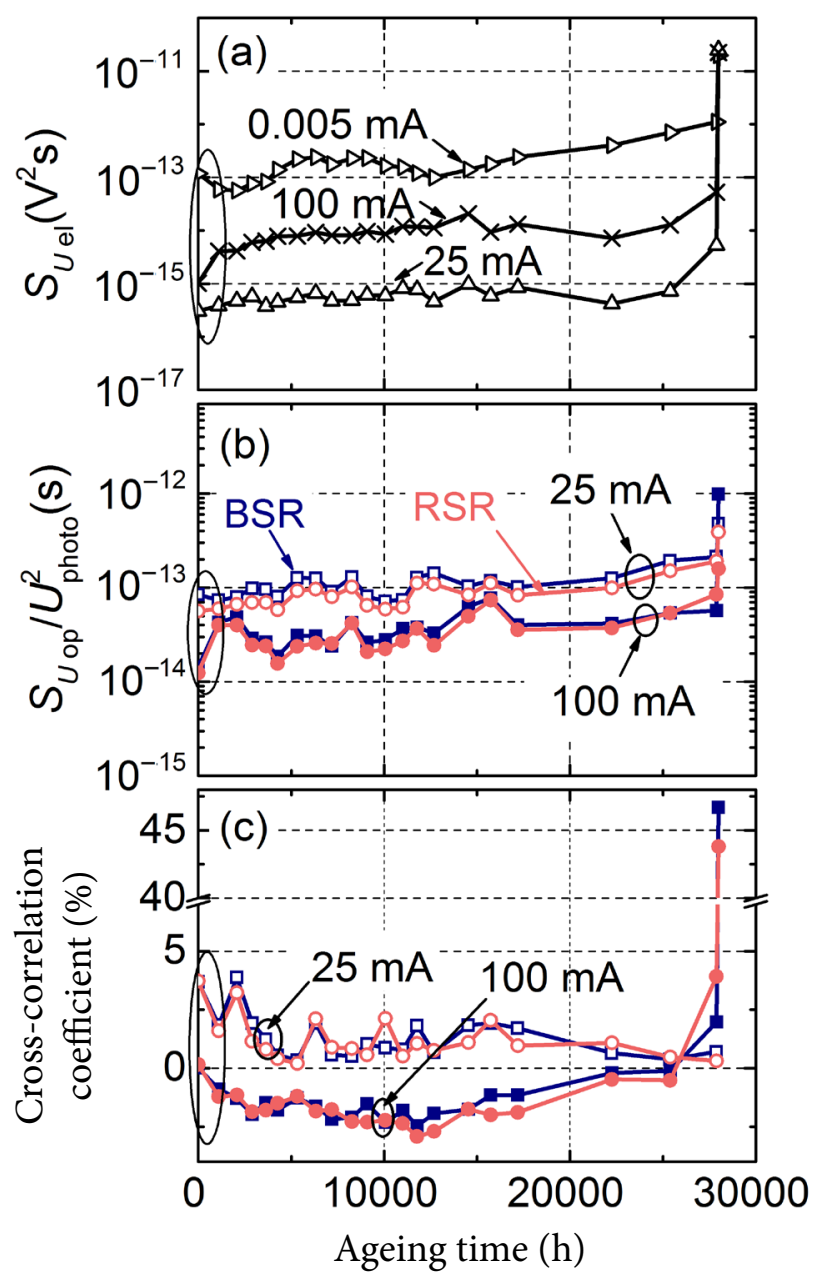

Fig. 5. Dependences of the electrical (a) and normalized optical noise (b) on the ageing time at different forward current values at $22 \mathrm{~Hz}$ and the dependence on the ageing time of the cross-correlation coefficient between electrical and optical fluctuations in the overall frequency range $10 \mathrm{~Hz}-20 \mathrm{kHz}$ at different forward current values (c). Circles denote the initial stage of ageing $(1100 \mathrm{~h})$.

$1 / f^{\alpha}$-type over all the investigated frequency range. At the initial stage of ageing, the voltage spectral density of electrical noise decreases when current flowing through the specimen is small $(0.005 \mathrm{~mA})$. However, at 25 and $100 \mathrm{~mA}$, the electrical noise increases by one order of magnitude compared to the unaged sample noise level. This increase of the electrical noise level in the higher current region can be attributed to the electromigrationinduced void formation in contact metallization [3]. In the low current region the noise level decreases more presumptively due to defect reordering or annealing [17] which determines fluctuations in the parallel leakage resistance value.
These material migration and reordering processes also influence changes in the potential barrier and, as a consequence, determine light output power increase after $1100 \mathrm{~h}$.

In order to calculate the cross-correlation coefficient, the optical noise (Fig. 5(b)) during ageing has been measured. The character of the voltage spectral density of optical fluctuations remains the same during all experiment $-1 / f^{\alpha}$-type at low frequencies which is prevailed by the shot noise at higher ones. The cross-correlation coefficient between electrical and optical fluctuations becomes negative in all investigated frequency range at $I=100 \mathrm{~mA}$ after $1100 \mathrm{~h}$ (Fig. 5(c)). This slightly negative cross-correlation at higher currents indicates forward current redistribution between the active and neighbour regions [16].

Between the initial and the final stages of ageing the series resistance of the investigated LED increases gradually and the leakage current also increases slightly, as seen from $I-V$ (Fig. 4). Such behaviour is quite common for GaN-based optoelectronic devices during ageing tests [3, 9]. While these changes are small (a number of additional non-radiative recombination centres is not high enough), they practically do not affect the light output characteristic. However, the increase of the electrical noise level is more noticeable in the region where the leakage current dominates $(0.005 \mathrm{~mA})$, while at higher forward current values only a small variation of noise intensity is observed (Fig. 5(a)). Also, small variations in the optical noise level and the cross-correlation coefficient dependences on the ageing time are observed between these stages (Fig. 5(b, c)).

The final ageing stage, which is accompanied by a strong growth of the spectral density of electrical noise (more than two orders) in all forward current range (Fig. 5(a)), should be distinguished. This is in coincidence with $I-V$ changes (Fig. 4) indicating the presence of parasitic leakage paths and also with a considerable light output power decrease (Fig. 3(b)) revealing the formation of a high number of non-radiative recombination centres. The increased optical noise level and especially the increased positive cross-correlation coefficient between the electrical and optical fluctuations (Fig. 5(b, c)) indicate high defectiveness of the LED active area. However, it is useful to separate the electrical low-frequency noise 
components into correlated and uncorrelated parts which can prove this idea.

As mentioned in the Introduction, the crosscorrelation method enables estimating which part of the electrical low-frequency noise is related to the optical fluctuations (this is represented by the quantity $d_{\mathrm{j}}$ that shows which part of the spectral component $S_{\text {el } j}(f)$ of the electrical noise is correlated to the emitted light fluctuations) and gives useful information on the noise origins in the device. In Fig. 6 the result of the calculation of quantity $d_{j}$ during the ageing is presented. The cross-correlation method has been fully described earlier in [10, 14]. Here, the index $j=1$ describes the variance of $1 / f$ fluctuations and $j=2$ is the variance of $1 / f^{\alpha}$ fluctuations (the shot noise and the noise of the measuring system are uncorrelated).

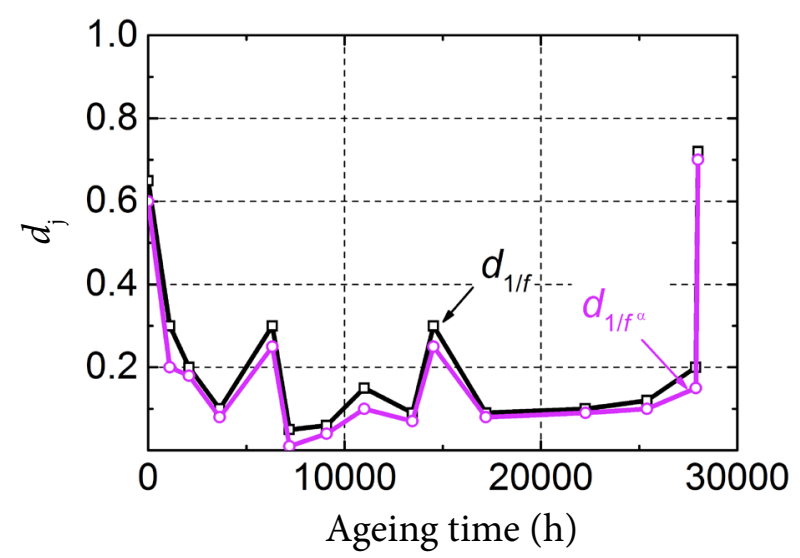

Fig. 6. Dependences of quantities $d_{\mathrm{j}}$ on the ageing time at $I=25 \mathrm{~mA}$.

Before ageing at $I=25 \mathrm{~mA}$ (where a maximum of the cross-correlation dependence on forward current is present (inset in Fig. 2(c)) quantities $d_{\mathrm{j}}$ for the $1 / f$ and $1 / f^{1.3}$ noise components have similar values: $d_{1 / f}=0.65$ and $d_{1 / f}{ }^{\alpha}=0.6$. These results mean that more than a half of the electrical low-frequency fluctuations are related to the lowfrequency optical fluctuations. After the initial ageing stage, the correlated part of electrical fluctuations decreases and this is in coincidence with the abovementioned idea of material migration and contact degradation: the electrical noise level increases due to noise sources in the passive layers of the LED. And at the final ageing stage there is a sudden increase in quantities $d_{j}$ exceeding their values before ageing: $d_{1 / f}=0.72$ and $d_{1 / f}{ }^{\alpha}=0.7$. This verifies a sudden growth of the noise source in the active area of the LED.

The most plausible reason of such abrupt changes of noise and $I-V$ characteristics after $28000 \mathrm{~h}$ of ageing is an increased self-heating of the device which has led to rapid defect formation, migration and clustering mostly in the active area of the LED. As reported in [2, 3], it can be related to a partial detachment of the layer containing the semiconductor chip from the package base, the so-called delamination, when a small air gap occurs between the LED chip and the package base. This strongly accelerates degradation of the device.

\subsection{Changes of optical characteristics influenced by the phosphor layer}

Changes in the performance of the phosphor layer have an impact on the alteration of optical characteristics (e.g. decrease in optical power) and the correlated colour temperature (CCT) shift. Also, as the optical noise is modulational, the LED current fluctuations modulate the emitted 'blue' photon flow, then this 'blue' photon flow modulates the 'yellow' emittance of the phosphor layer, and the determination whether this additional layer acts as a noise source is possible.

Figure 7 represents the optical spectra of the investigated LED during the ageing experiment, which is typical of the white LED: it is composed of

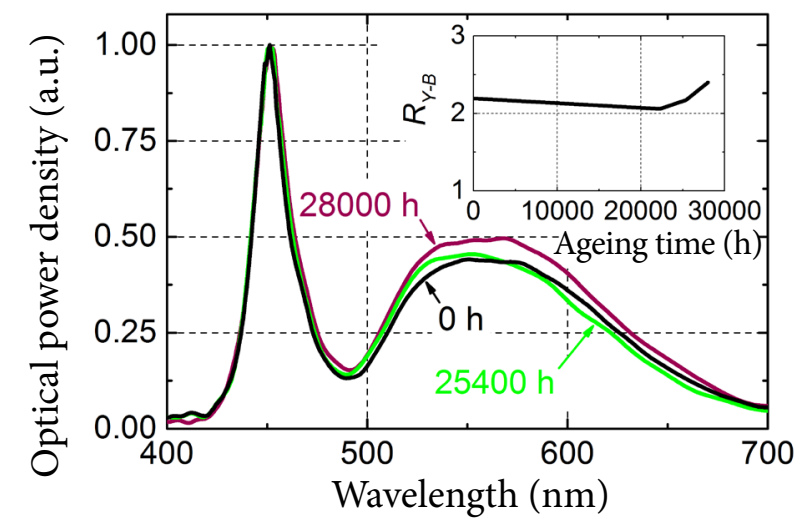

Fig. 7. Optical spectra measured at $100 \mathrm{~mA}$ forward current after different ageing time. All spectra are normalized to the peak of the 'blue' radiation. The inset shows the variation of the $R_{\mathrm{Y}-\mathrm{B}}$ ratio during the ageing experiment. 
the blue part of the spectrum up to $480 \mathrm{~nm}$ produced by the LED chip and the remaining yellow part due to the partial conversion of the chip radiation by the phosphor layer.

There is no significant wavelength change in the blue part of the spectrum (the central wavelength $\lambda=452 \mathrm{~nm}$ ) during ageing. The ratio $R_{\mathrm{Y}-\mathrm{B}}$ between intensities of the yellow and the blue parts of the optical spectrum is calculated as follows:

$$
R_{\mathrm{Y}-\mathrm{B}}=\frac{\int_{480}^{780} P(\lambda) \mathrm{d} \lambda}{\int_{380}^{480} P(\lambda) \mathrm{d} \lambda} .
$$

Here $P(\lambda)$ is the optical power density (W/nm). This ratio varies during the ageing experiment. It slightly decreases up to $22260 \mathrm{~h}$ and then starts to increase indicating colour changes of the emitted light. In some applications, e.g. in museum lighting or medicine, chromatic stability is very important. The colour shift of light is represented in the CIE 1931 colour space (Fig. 8) where $x, y$ and $z$ are chromaticity coordinates and $z=1-x-y$, so it can be depicted in the Cartesian plane. Applying the third order polynomial equation [18], the correlated colour temperature (CCT) has been computed using the CIE 1931 coordinates $x, y$. Generally, the main factors that influence chromatic

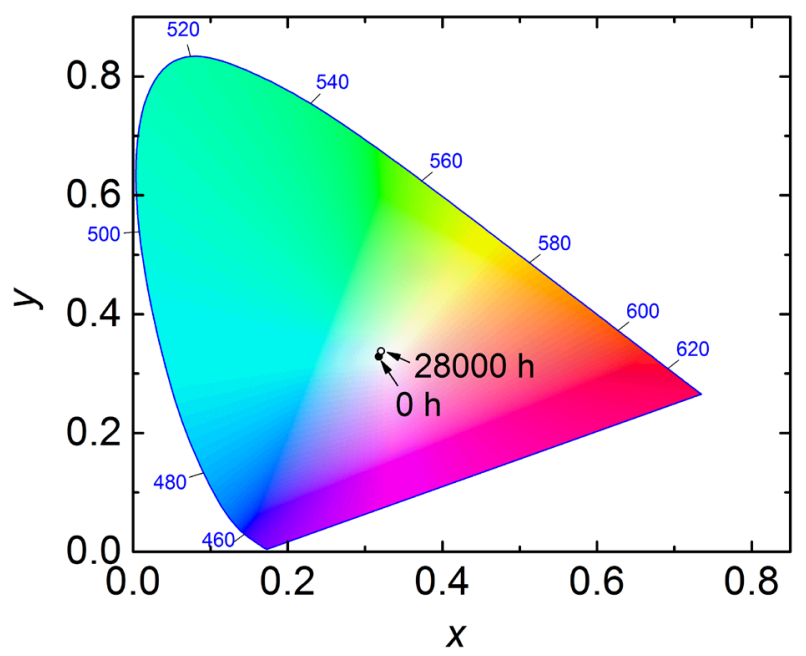

Fig. 8. Variation of the CIE 1931 chromatic coordinates measured before (CCT $6225 \mathrm{~K}$ ) and after the $28000 \mathrm{~h}$ ageing experiment (CCT $6040 \mathrm{~K}$ ) at $100 \mathrm{~mA}$ forward current. properties of the LED are blue LED chip degradation, change in phosphor layer efficiency and darkening of the phosphor-encapsulating material [2]. The change of CCT from the initial $(0 \mathrm{~h}) 6225 \mathrm{~K}$ to $6306 \mathrm{~K}$ after $22600 \mathrm{~h}$ of ageing can be related to the decrease of the phosphor layer efficiency as the blue light output power of the chip is practically stable (excluding the initial light output increase just after $1100 \mathrm{~h}$ ) (Fig. 2(b)). As stated in [19], the increase in the phosphor conversion efficiency is possible only during the early ageing stage. At the same time, browning of the phosphor-encapsulating material also takes place. While all these factors contribute to the LED light output degradation, their rate of kinetics differs [5]. During ageing, these rates vary, so this affects chromatic properties of the device differently. The yellowing of optical spectra of the investigated sample after $22260 \mathrm{~h}$ is also confirmed by the light output measurement (Fig. 2(b)): the optical power measured with RSR oversteps the light power measured with the BSR photodiode despite the fact that the general light output decreases. The calculated CCT after the $28000 \mathrm{~h}$ ageing experiment is $6040 \mathrm{~K}$. So, the variation of chromatic properties of the investigated LED is determined by a volatile ratio between the blue and yellow components of optical spectra.

From the noise point of view, there is a quite good agreement between the cross-correlation coefficient dependences on the frequency when the optical noise is measured with the BSR photodiode, and when it is measured with the RSR photodiode, during all the ageing experiment (Fig. 5(c)). The phosphor layer only reemits part of the LED chip radiation and the changes in the efficiency of this layer affect just the level of the optical fluctuations measured with RSR. These phosphor layer efficiency fluctuations are very small, so they do not cause a significant mismatch between BSR and RSR cross-correlation coefficient values. Thus, it can be stated that the phosphor layer practically does not act as an additional noise source in the investigated ageing time interval. The main source of the optical noise is the active area of the LED.

\section{Conclusions}

The investigation of noise characteristics and other supplementary electrical and optical characteristics 
(I-V, light output power, optical spectra) of a high-power InGaN white phosphor-converted LED has been performed during the long-term $(28000 \mathrm{~h})$ ageing experiment.

At the initial stage of ageing $(1100 \mathrm{~h})$, the increase of light output and the decrease of electrical noise at the small forward current region are related to annealing or reordering of some defects leading to potential barrier changes. The growth of the electrical noise level at larger currents is mostly caused by contact degradation which is supported by $I-V$ and negative cross-correlation characteristics indicating forward current redistribution between the active (QW region) and the neighbour areas.

Between the initial and the final stages of ageing, small variations occur in the optical and electrical noise intensity, and the correlated electrical noise part decreases.

The final stage of ageing is characterized by a high electrical and optical noise growth and a strong positive cross-correlation between them, indicating a high defectiveness of the active area of the LED.

The obtained calculation results using the cross-correlation method prove this idea. At this stage in the active area current leakage paths are formed by defects that act as non-radiative recombination centres and thus considerably lower light output power. The most presumable reason of this damage of the active area is the increased device self-heating.

A clear coincidence of two cross-correlation coefficient measurements, between electrical and LED blue light intensity fluctuations and between electrical and phosphor radiation intensity fluctuations, shows that the phosphor layer does not act as a noise source at given ageing conditions and time. However, this layer contributes to the variation of chromatic properties of the LED. Due to different kinetic rates of the degradation of separate LED parts (chip, the phosphor layer and the encapsulating material) two different CCT shifts are observed during the ageing experiment.

\section{References}

[1] M. Yazdan Mehr, W.D. van Driel, and G.Q. Zhang, Accelerated life time testing and optical degrada- tion of remote phosphor plates, Microelectron. Reliab. 54, 1544-1548 (2014).

[2] M. Meneghini, L.R. Trevisanelloa, F. de Zuania, N. Trivellin, G. Meneghesso, and E. Zanoni, Extensive analysis of the degradation of Phosphor-Converted LEDs, Proc. SPIE 7422, $74220 \mathrm{H}-1$ (2009).

[3] A. Jayawardena and N. Narendran, Analysis of electrical parameters of InGaN-based LED packages with aging, Microelectron. Reliab. 66, 22-31 (2016).

[4] J. Fan, K.-C. Yung, and M. Pecht, Lifetime estimation of high-power white LED using degradation-data-driven method, IEEE Trans. Device Mater. Reliab. 12(2), 470-477 (2012).

[5] M. Yazdan Mehr, W.D. van Driel, and G.Q. Zhang, Reliability and lifetime prediction of remote phosphor plates in solid-state lighting applications using accelerated degradation testing, J. Electron. Mater. 45(1), 444-452 (2016).

[6] B.K. Jones, Electrical noise as a reliability indicator in electronic devices and components, IEE Proc. Circ. Dev. Syst. 149, 13-22 (2002).

[7] L.K.J. Vandamme, Noise as diagnostic tool for quality and reliability of electronic devices, IEEE Trans. Electron Dev. 41, 2176-2187 (1994).

[8] S. Bychikhin, D. Poganya, L.K.J. Vandamme, G. Meneghesso, and E. Zanoni, Low-frequency noise sources in as-prepared and aged $\mathrm{GaN}$ based light-emitting diodes, J. Appl. Phys. 97, 123714 (2005).

[9] S. Sawyer, S.L. Rumyantsev, and M.S. Shur, Degradation of AlGaN-based ultraviolet light emitting diodes, Solid State Electron. 52, 968-972 (2008).

[10]V. Palenskis, J. Matukas, S. Pralgauskaite, and B. Saulys, A detail analysis of electrical and optical fluctuations of green light-emitting diodes by correlation method, Fluct. Noise Lett. 9(2), 179192 (2010).

[11]K.K. Leung, W.K. Fong, and C. Surya, Lowfrequency noise in $\mathrm{GaN}$ diodes, in: Proceedings of the 21st International Conference on Noise and Fluctuations (IEEE, 2011) pp. 291-296.

[12]I.-H. Lee, A. Y. Polyakov, S.-M. Hwang, N.M. Shmidt, E.I. Shabunina, N.A. Tal'nishnih, 
N.B. Smirnov, I.V. Shchemerov, R.A. Zinovyev, S.A. Tarelkin, and S.J. Pearton, Degradationinduced low frequency noise and deep traps in GaN/InGaN near-UV LEDs, Appl. Phys. Lett. 111, 062103 (2017).

[13]L. Liu, J. Yang, and G. Wang, The investigation of LED's reliability through highly accelerated stress testing methods, in: Proceedings of the 14th International Conference on Electronic Materials and Packaging (EMAP) (IEEE, 2012) pp. 1-3.

[14]V. Palenskis, J. Matukas, and B. Šaulys, A detailed analysis of electrical and optical fluctuations of light-emitting diodes by correlation method, Lith. J. Phys. 49, 453-460 (2009).

[15]V. Palenskis and K. Maknys, Nature of low-frequency noise in homogenous semiconductors, Sci. Rep. 5, 18305 (2015).
[16]V. Palenskis, J. Matukas, and S. Pralgauskaité, Light-emitting diode quality investigation via low-frequency noise characteristics, Solid State Electron. 54(8), 781-786 (2010).

[17]J. Hu, L. Yang, L. Kim, and M.W. Shin, The ageing mechanism of high-power InGaN/GaN light-emitting diodes under electrical stresses, Semicond. Sci. Technol. 22, 1249-1252 (2007).

[18]C.S. McCamy, Correlated color temperature as an explicit function of chromaticity coordinates, Color Res. Appl. 17(2), 142-144 (1992).

[19]Z. Qin, J. Feng, C. Zhaohui, X. Ling, W. Simin, and L. Sheng, Effect of temperature and moisture on the luminescence properties of silicone filled with YAG phosphor, J. Semicond. 32(1), 012002 (2011).

\title{
DIDELĖS GALIOS BALTOS ŠVIESOS DIODO ŽEMADAŽNIO TRIUKŠMO CHARAKTERISTIKOS ILGALAIKIO SENDINIMO EKSPERIMENTO METU
}

\author{
J. Glemža, J. Matukas, S. Pralgauskaitė, V. Palenskis \\ Vilniaus universiteto Taikomosios elektrodinamikos ir telekomunikaciju institutas, Vilnius, Lietuva
}

\begin{abstract}
Santrauka
Ilgalaikio sendinimo eksperimento metu (28000 val.) tirtos didelès galios InGaN pagrindu pagaminto baltos šviesos diodo žemadažnio elektrinio ir optinio triukšmo charakteristikos bei jų tarpusavio koreliacijos koeficientas. Koreliacinè analizè rodo, kad koreliuoto žemadažnio elektrinio triukšmo dalis, kuri atspindi fizikinius procesus, vykstančius šviesos diodo aktyviojoje srityje, sendinimo eksperimento metu kinta. Atsižvelgiant $\mathfrak{i}$ staigius triukšmų charakteristikų pokyčius išskiriami du pagrindiniai etapai. Pradinis etapas (po pirmųjų 1100 val.) yra susijęs su elektrinio triukšmo mažejimu tekant bandiniu mažoms srovèms ir spinduliuotès galios padidejimu, o
\end{abstract}

galutinis etapas (po 28000 val.) charakterizuojamas staigiu žemadažnio triukšmo augimu, spinduliuotès galios sumažejjimu ir elektrinio triukšmo koreliuotosios dalies su optiniu triukšmu didejimu. Tai rodo aktyviosios srities gedimą. Optinio spektro skaidymas ị puslaidininkio šviesos diodo lusto spinduliuotę ir perspinduliuotą fosforo sluoksnio leidžia ịvertinti fosforo sluoksnio ịtaką prietaiso optiniu charakteristiku blogejjimui. Nepaisant to, kad šis sluoksnis itin prisideda prie šviesos diodo chromatiniu savybiu kitimo, tarpusavio koreliacijos koeficiento analizè rodo, kad fosforo sluoksnis sendinimo eksperimento metu nèra triukšmo šaltinis. 